\title{
Where Common Core meets effective transition: You can have a job
}

\author{
Linda H. Rammler ${ }^{\mathrm{a}, *}$ and Michelle L. Ouimette ${ }^{\mathrm{b}}$ \\ ${ }^{\text {a }}$ Discover Learn Work Career Training Services, Guilford, CT, USA \\ ${ }^{\mathrm{b}}$ Roses For Autism and Ability Beyond Transition Services, Bethel, CT, USA
}

Revised/Accepted December 2015

\begin{abstract}
.
BACKGROUND: We groaned, too, when we learned about the Common Core and considered how it could affect thoughtful, appropriate and evidence-based transition services if not carefully implemented.

OBJECTIVE: Without watering down either, we have developed a model demonstration project that meets the needs of late adolescents/young adults with autism, autistic-like presentations, mental health/behavioral challenges, and other developmental disabilities by successfully preventing them from falling off "The Cliff" between IDEA-mandated and eligibility-based, underfunded adult services when they exit out of IEP-land. How? By helping them to achieve employment prior to exiting IDEA-funded services.
\end{abstract}

CONCLUSION: This paper discusses the challenges presented by the Common Core and describes what the components of our model are in response to these standards.

Keywords: Transition, employment, IDEA, outcomes, challenges, Common Core

\section{Introduction}

A number of authors have identified a range of valued life outcomes for people with autism, autistic-like presentations, mental health/behavioral challenges, and developmental disabilities (Layard, Clark, Cornaglia, Powdthavee, \& Vernoit, 2014; Ruble \& Dalrymple, 1996; Stewart, Kum, Barth, \& Duncan, 2014; Smull, Sanderson, Sweeney, Skelhorn, George, $\&$ Bourne, 2005). There is also substantial literature on the common barriers that still prevent everyone with these labels from fully achieving those valued life outcomes (Francis, Gross, Turnbull, \& Turnbull, 2014; Lindsay, McDougall, Menna-Dack, Sanford, \& Adams, 2014). One major barrier is what we call "The Cliff" - i.e., the reality of transitioning from IDEAmandated services provided by public schools to

*Address for correspondence: Linda H. Rammler, M.Ed., Ph.D., CESP, Director, Discover Learn Work Career Training Services, 929 Boston Post Road, Guilford, CT 06437, USA. Tel.: +1 475529 1750; E-mail: linda.rammler@abilitybeyond.org. non-mandated and often severely underfunded adult services (c.f., Riesen, Schultz, Morgan, \& Kupferman, 2014). Because of "The Cliff," we know that too many young adults who have prematurely accepted their diplomas from their school districts, or who have aged out and are no longer eligible for mandatory services, are unemployed or underemployed and relegated to a life of poverty (Wehman et al., 2014). In contrast, valued life outcomes such as having a job, the opportunity to earn money, and the ability to spend that money, e.g., for a place of their own to call home, are just assumed for - and taken for granted by - their same-aged peers without disabilities.

In this article, we discuss the relationship between state implementation of the Common Core (Common Core State Standards Initiative, 2015a) for those receiving IDEA-funded transition services and the challenges school districts face in meeting Common Core standards in a way that maximizes each individual's valued life outcomes and greatly reduces the risk of "The Cliff." We then describe critical 
components of a model demonstration project, now in its third year, which successfully has addressed the challenges of Common Core implementation resulting in a comparably seamless transition to adult services with the level of support an individual may continue to need in the short or long term. This project is guided by the principle that working for real pay vastly increases the probability of accessing what you need to achieve a personally satisfying and self-determined life (Yoshikawa, Aber, \& Beardslee, 2012). In the last section, we recommend strategies at the grassroots and policy levels for maximizing the probability that transitioning students have meaningful employment prior to graduation to assure transition-aged students avoid "The Cliff" because what they can access from non-mandated adult services is insufficient to meet their needs as adults.

\section{Common Core or common vision?}

"To ensure all students are ready for success after high school, the Common Core State Standards establish clear, consistent guidelines for what every student should know and be able to do in math and English language arts from kindergarten through 12th grade" (Common Core State Standards Initiative, 2015b). This is the primary purpose of national learning standards according to the website of the Common Core State Standards Initiative: Preparing America's Students for College and Career. As of this writing, "forty-two states, the District of Columbia, four territories, and the Department of Defense Education Activity (DoDEA) have adopted the Common
Core State Standards" (Common Core State Standards Initiative, 2015c, p.1) for English/Language Arts (ELA) and Math. Some states, like Connecticut (CT), also have a statewide curriculum in other content areas that align with the ELA and Math standards. These other content areas include Arts, Career and Technical Education, Health, Information and Communication Technologies, Physical Education, Science, Social Studies, and World Languages (Connecticut State Department of Education, 2015). Additionally, in 2013, CT developed standards for transition, encouraging school districts “... to use these for all students with an IEP, at least for students ages 15-21 and preferably for younger students as well... The CSDE feels strongly that if these key CORE skills are addressed, if not mastered, all students with disabilities will be significantly better prepared to meet their post-school goals after exiting from high school (emphasis added) (Connecticut Transition Task Force, 2013). These appear in Table 1.

Although these skills are desirable for transitionaged students, they fall short of encouraging students, parents, and school staffs to look beyond what is taught to what is positive and possible (Pearpoint, O'Brien, \& Forest, 1993; Theoharis \& Causton, 2014 ) in all students' futures. Rather, adolescents and young adults, to the extent possible, should meaningfully be employed upon graduation from secondary and/or transition services. They also should be living meaningful lives. In this article, we identify and define five (5) valued life outcomes. These appear in Table 2. It is from these that additional valued life outcomes such as a place of one's own to call home,

Table 1

State Education Resource Center Connecticut State Department of Education Connecticut CORE Transition Skills

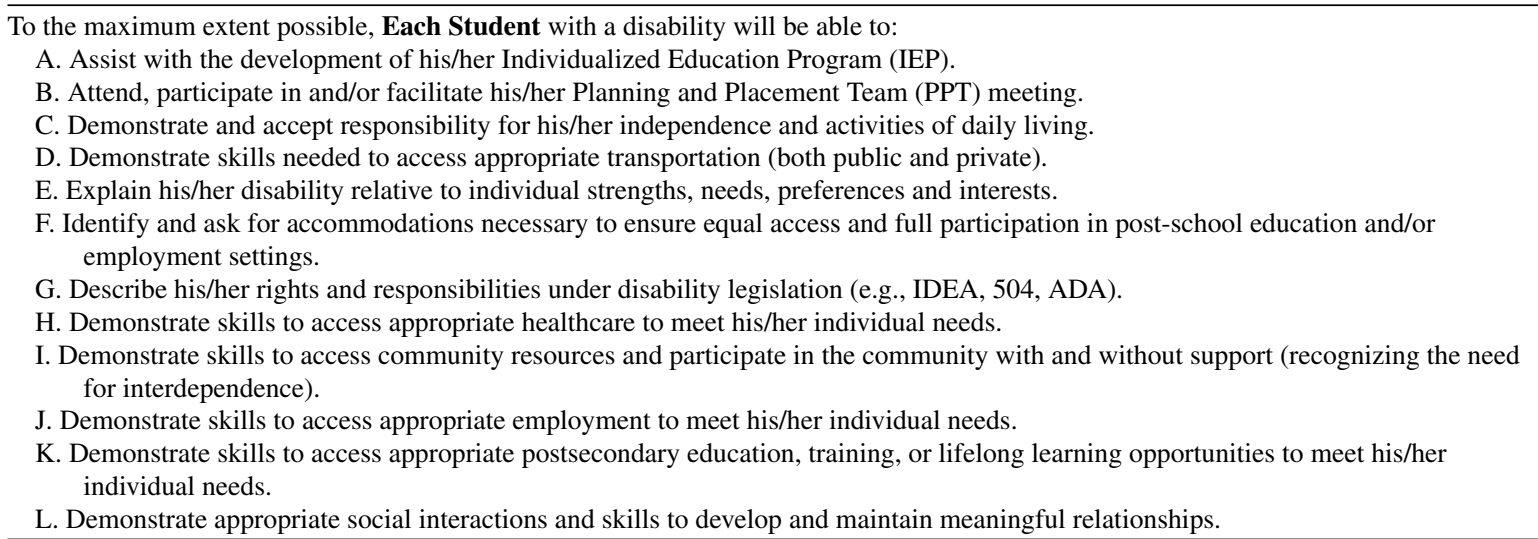

(Connecticut Transition Task Force. (2013). Connecticut CORE Transition Skills. Retrieved from http://www.cttech.org/sss/documents/ CT\%20CORE\%20Transition\%20Skills\%20May\%202013\%20Final2.pdf) 
satisfying opportunities for leisure and recreation, etc., are made possible.

We assert that, as long as receipt of necessary adult services is not considered a national right for those with disabilities, it must then become the responsibility of the planning and placement team (PPT) to enable individuals to achieve these outcomes. Our company policy mirrors that of TransCen, Inc., in Maryland, another transition and employment agency:

Transition Services at Ability Beyond

All young people with disabilities deserve the opportunity for seamless transition into adulthood. Seamless transition occurs when the first day after graduation looks the same for youth as their last day of school. That is, they exit school already into an integrated job, with supports in place to keep this job. And not only that, services are available to support the acquisition of new jobs and career advancement throughout their adult life.

Features of a Seamless Transition Model

- Work experiences throughout secondary school years that help students identify interests, skills and supports relevant to the attainment of adult employment

- Employment in integrated settings during their last year of school where they are hired directly by the employer

- Non-work activities performed in normalized community settings,

- Adult agency employment specialists working in conjunction with school personnel before school exit

- Cost sharing resources of the school system, state vocational rehabilitation services, and state intellectual/developmental disabilities agency, and

- An outcome of paid work with post-school support in place before school exit.

We will make our vision, outlined below, a reality by tapping the most important players in the life of a young adult with disabilities: his or her family, school and the service agencies that provide resources and guidance.

Further, we know Congress intended, in the 2004 Amendments to the Individuals with Disabilities Education Improvement Act of 2004 (IDEA) (IDEA, 2004) and the accompanying regulations (Assistance to States for the Education of Children With Disabilities and Preschool Grants for Children With Disabilities, 2006) to increase post-graduate outcomes for students but what it effectively did, using language that implies the responsibility of school districts is optional, was to move "The Cliff" from age 18 to 21 in most states. Although the 2004 and 2006 federal documents imply that school districts are required to do more that just prepare students for post-secondary life, the extent of preparation is subject to local politics, restricted school budgets, and the systemic cliff between them and adult services providers. As a result, even with exceptional transition services, too many young adults remain unemployed and at home from their last day of school in June until their adult services funding begins.

As one example, in Connecticut in 2015, there were no funds for "new graduates" eligible for Home and Community Care Waiver-funded services under the auspices of our state Department of Developmental Services so that, unless families could afford to pay privately or organizations were able to provide schol-

Table 2

Valued Life Outcomes for People with Autism, Autistic-Like Presentations, Mental Health/Behavioral Challenges, and Developmental Disabilities

\begin{tabular}{lc}
$\begin{array}{l}\text { Meaningful employment } \\
\text { upon exiting school } \\
\text { with opportunities for } \\
\text { the future }\end{array}$ & $\begin{array}{c}\text { Employment that matches one's interests, preferences, skills, and abilities and that provides opportunities for } \\
\text { benefits, advancement, social fulfillment, and personal satisfaction. (See Novak, 2015) }\end{array}$ \\
$\begin{array}{l}\text { Chronologically } \\
\text { Age-appropriate } \\
\text { interdependence }\end{array}$ & $\begin{array}{r}\text { No one Is fully independent. Rather, we are interdependent on and with others in our circles of support and } \\
\text { communities. Chronologically age-appropriate interdependence means that adults with disabilities are not } \\
\text { treated like children by their families, the general public, and service providers. }\end{array}$ \\
$\begin{array}{l}\text { Livable income } \\
\text { Defined by the individual, a livable income is sufficient to meet one's basic necessities as well as allow one to } \\
\text { access the people, things, activities/events, or other opportunities to create a satisfying life. }\end{array}$ \\
$\begin{array}{l}\text { Companionship and } \\
\text { Companionship means having access on a regular basis to people with whom one has a mutually satisfying } \\
\text { relonging }\end{array}$ \\
$\begin{array}{c}\text { relionship so that one does not experience chronic loneliness. "Belonging" is a basic human need to feel } \\
\text { Sense of purpose and } \\
\text { dignity }\end{array}$ & $\begin{array}{l}\text { As defined in 2006 by the United Nations Convention on the Rights of Individuals with Disabilities (Source: } \\
\text { http://www.un.org/disabilities/convention/conventionfull.shtml, retrieved December 15, 2015) }\end{array}$ \\
\hline
\end{tabular}


arships, no services were available until five months or more after they accepted their diplomas. Even though the funding has substantially been restored, for some the wait has been as long as six months. Six months in which to lose skills, motivation, and self-confidence that school district staff worked so diligently to build. We constantly receive referrals from individuals who have been staying at home for much longer. Simply having and implementing a Common Core does not automatically mean that one can have a job after exiting secondary school.

\section{Common "Common Core" requirements/challenges}

Regardless of any state's common core, a critical question to answer is "How much emphasis is there on continued academics?" If there is considerable emphasis on continued academics, whether or not these are supposed to be functional in nature or a continuation of a college preparatory high school curriculum, we then have to ask "How truly prepared are adolescents/young adults going to be?" The core "preparational" transition standards in Connecticut in addition to a bank of goals and objectives subsequently developed to accompany those skill areas (CSDE, 2004) appears only to focus on knowledge competencies and skill demonstration and/or academics for transition services that do not necessarily translate into valued life outcomes. In fact, in our work, we have seen how these can be counterproductive if valued life outcomes are to occur because, particularly for the young adult population, one size does not fit all. Far too often, students are required to exit high school still requiring adult supports because skill mastery either is highly unlikely to occur or will not be applicable (given, for example, the lack of public transportation in many of CT's rural areas).

\subsection{Examples}

Let's take, for example, CT's Core Standard L: "Demonstrate appropriate social interactions and skills to develop and maintain meaningful relationships." The goal bank offers, as one way to demonstrate this core transition skill, the following statement: "Student will participate in at least one extracurricular activity in order to develop nonacademic aspects of learning (p.3)." Another goal option is "Student will appropriately confront topics/issues which are uncomfortable, with teacher/para support (p.5)." We have found that a more important bottom line is to explore these questions through the PPT: Who is in their lives now? Who will be in adulthood? Are these sufficient connections for meaningful employment and personal success? What are we going to do about it before it's too late? To us, the focus on student learning at this stage seems disconnected to what the literature on adult community living states are critical components of adult success.

Here is another example of this disconnect: The actual standard ( $\mathbf{J})$ is "Demonstrate skills to access appropriate employment to meet his/her individual needs." Samples from the accompanying goal bank include "Student will complete a minimum of two job reports on occupations of interest (p.4)" and "Student will successfully complete school-supervised work experiences (p.4)." While these "goals" really are strategies for some, they will not enable others to gain "appropriate employment." We also believe the statement "meeting his/her individual needs" is actually the same for all because those needs really are those valued life outcomes.

A third example of the disconnect (Standard D) is that students will "Demonstrate skills needed to access appropriate transportation (both public and private)." The goal bank offers "Student will read and follow directions, maps, signs and transportation schedules," "Student will receive additional tutorial support to pass the written driver's license examination," and "Student will learn the skills to access public transportation" (p.7). For us, the bottom line really is "How are we assuring that these students, upon exiting high schools, will actually be able to get from where they are to where they need to go?"

\section{The need for truly outcomes-oriented core standards}

We have learned, as have others, through membership in such organizations as TASH and the Association of People Supporting Employment First, that "ready means never" for too many individuals, particularly those most likely to require lifelong supports. We also know that skill demonstration in artificial environments and/or with artificial supports leads to disappointment on the parts of students, families, and employers after "aging out" occurs. One particularly poignant example was when a parent and school team developed a paying job in what was a perfect environment for the 20-year-old student. The 
student took the exact same transportation to and from this job placement before accepting his high school diploma. However, because of liability concerns, a $1: 1$ job coach accompanied the student on the public transportation and, while waiting for the student to complete his/her assignment given by the employer, provided verbal prompting in the actual employment setting. Clearly, this student "demonstrated skills needed to access appropriate (public) transportation." However, this demonstration occurred under daily supervision and the reality was, without that supervision, the student was unsafe when there were any glitches in the mass transit schedule or if the roadway between the public transportation stop and the job had heavier than usual traffic. Had the parent and school team not found the job, however, the student was not able to "demonstrate skills to access appropriate employment to meet his individual needs" independently. In fact, without ongoing prompting, he was unable to work without ongoing on-the-job support.
Questions unanswered when the student graduated were: Given the lack of adult services funding, who would continue to work with the student until mastery was demonstrated? Were there natural supports or assistive technology to replace the $1: 1$ job coach more, if not all, of the time?

Under the IDEA, the $1: 1$ job coach was required to meet the student's transition goals and objectives. There is no such mandate in adult services. Who, then, will make sure the student can get safely to and from work and, once at work, be able to complete his assignments to the satisfaction of his employers in order to stay on payroll?

When teaching to core skills, the methodology is clear because instruction happens within the confines of a single system, i.e., that of the public school district. This methodology is depicted in Figure 1. The problem is not when this method works but rather when it doesn't ... or doesn't according to the time frame the public school has before the students ages

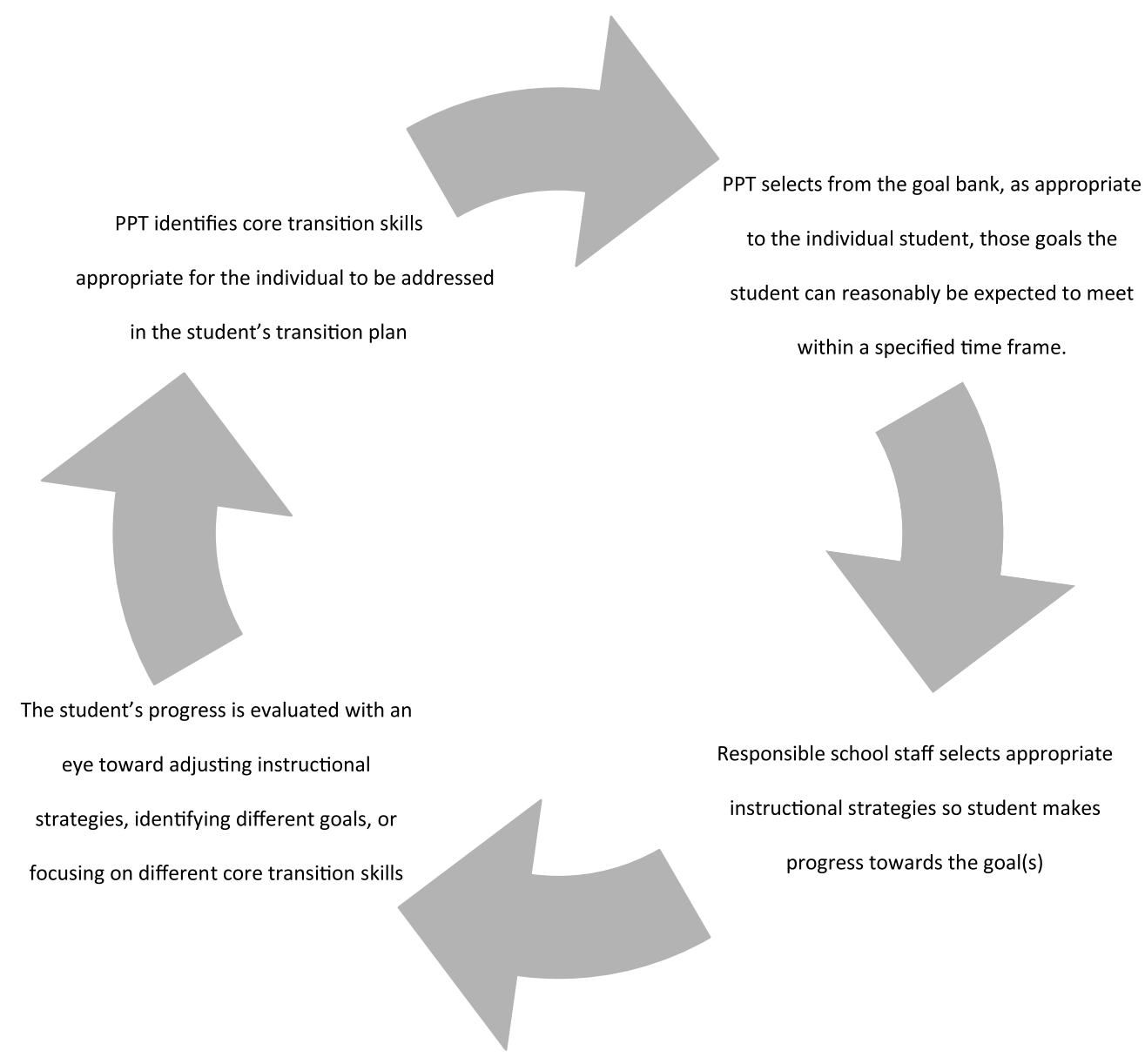

Fig. 1. Teaching to core skills cycle. 
out. This is why we have proposed, instead, a rewrite of common core transition standards that melds the real purpose of schools (i.e., student learning) with seamless transition, taking into account the nonmandated and chronically underfunded adult services and the need for the first day after exiting secondary education to look the same as the last day before exiting. Toward this end, we use our own version of CT's twelve core transition standards in CT as appears in Table 3.

\section{Our model}

For over 62 years, Ability Beyond, Inc., a private non-profit organization based in $\mathrm{CT}$, has led the field in supporting people with disabilities, by providing person-centered, cutting-edge, and costeffective services. Transition Services are one of an array of such services, one of which is called "Discover Learn Work Career Training Services (DLW)." Through a partnership with the University of CT Center for Excellence in Developmental Disabilities, we have developed a model demonstration program that addresses, head-on, the problem of how to assure valued life outcomes for the population we serve. These are transitioning youth and young adults with labels of autism, autistic-like presentations, mental health and behavioral challenges and other developmental disabilities.

DLW consists of four "pillars" of services (see Figure 2) which do not occur sequentially but rather

Table 3

An Outcomes-Oriented Re-write of CT's Core Transition Standards Used by Discover Learn Work Career Training Services

1. Develops own plans independently or with an identified level of assistance by a trusted member of his/her Circle of Support.

2. Runs own meetings independently or with an identified level of assistance by a trusted member of his/her Circle of Support.

3. Demonstrates maximum independence w/ADLs

4. Has access/can use necessary transportation with supports as needed.

5. Can or has an existing means to express or demonstrate strengths, interests, preferences, support needs to others independently or with an identified level of assistance by a trusted member of his/her Circle of Support.

6. Can advocate for appropriate accommodations independently or with an identified level of assistance by a trusted member of his/her Circle of Support.

7. Can advocate for legal rights independently or with an identified level of assistance by a trusted member of his/her Circle of Support.

8. Has access to and can access health care as needed with supports as needed.

9. Has access to/Can use available community resources for personal success with supports as needed.

10. Is meaningfully employed with supports as needed.

11. Can continue his/her education/lifelong learning with supports as needed.

12. Has meaningful relationships.

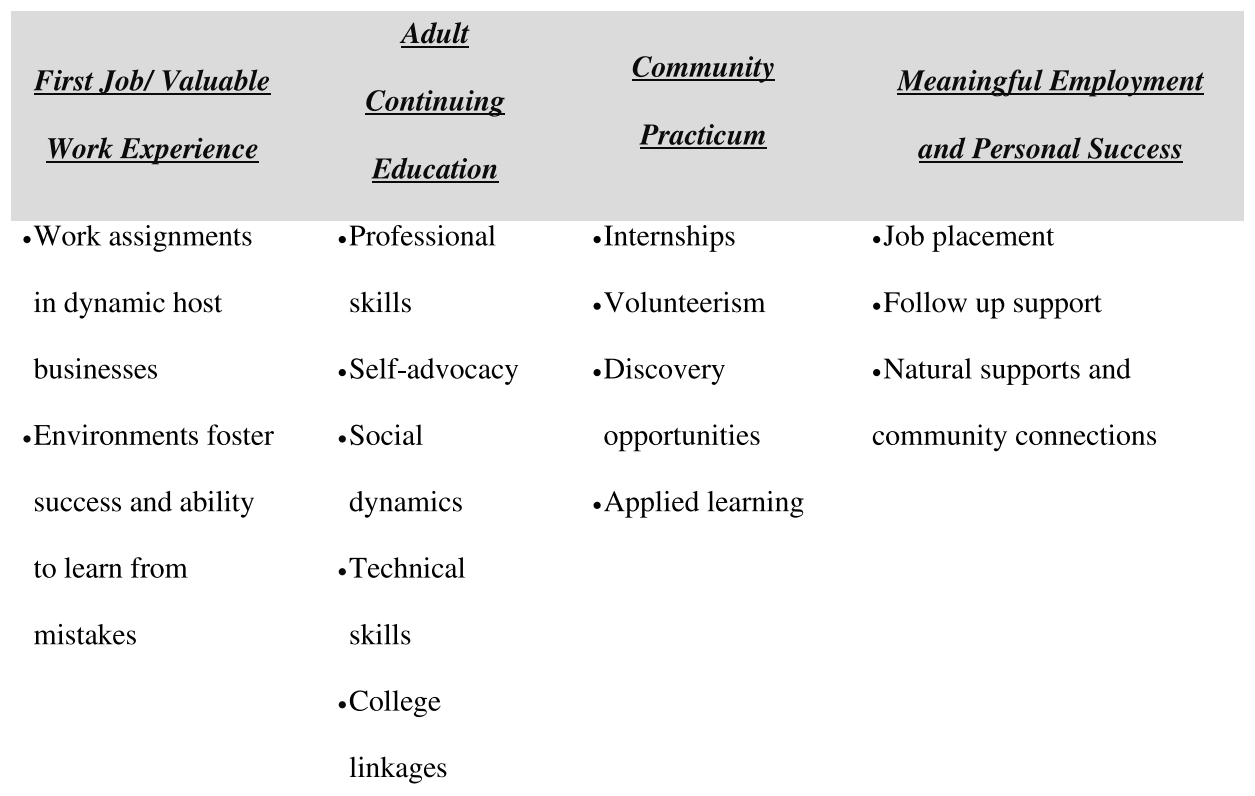

Fig. 2. Pillars of Discover Learn Work's Career Training Services. 
are individually planned based on each intern's person-centered career plans. Unlike many other providers of school and adult services, we do not predetermine what interns can and cannot do based on their prior histories of successes and failures, their test scores, or even the level of motivation they exhibit. Rather, we lead them through a discovery process - about themselves, the world of work, community resources, support them to learn what they need to know to make informed decisions about career and personal success goals and the skills they need to reach those goals, and then orchestrate meaningful employment through assistance with job applications and/or interviews, job development, job supports (which may include accessing assistive technology, on-site job coaching, or developing mentorships at their new place of employment).

Implementation of this model relied on the following components that reflect best practice in school-to-work transition and young adult services:

- Intensive/ongoing staff training and on-site technical assistance

- Partnerships with schools, businesses, Chamber of Commerce, funding agencies

- Entrepreneurial initiatives

- Leveraging contacts to broaden our reach

- Use of technology for individual supports, off-site consultation to employers, and troubleshooting.

In 2014-15, we increased the number of individuals we served from 25 to 50 . Of these, 22 never had transition services at all; eight (8) still had IEPs; and the rest had transition services based on the bare minimum). So far, our outcomes are as follows: five (5) have enrolled in certificate or degree programs, 13 are employed by others, and two (2) have become selfemployed. The satisfaction rate reported by interns is $94 \%$. When we compare these statistics to those of national outcomes for students with disabilities exiting IDEA-mandated services, we know this model is effective.

Nonetheless, there are systemic and cultural barriers to maintaining the model's fidelity and longevity. We recognize that these expected challenges have included and will continue to include:

- Time to build in for ongoing staff development within our service and for those with whom we interact.

- Lack of meaningful, individualized preparedness for ALL, resulting in a diverse group of interns who have very diverse levels of experiences

- Scheduling and logistics planning

- Parent fears and unrealistic expectations

- Fostering partnerships with businesses, avoiding their burnout, refreshing the pool

- Schools continuing to focus too much on classroom curriculum

- Adult services agencies not being full participants

- Lack of funding availability.

We continue to address these challenges through two sessions of summer services, a year-round service, and a vacation service to meet the needs of those youth and young adults who otherwise would fall through the cracks.

\section{Conclusion}

All young people deserve a thoughtful education that will unlock their potential and prepare them for success, on their own terms, when they enter adulthood. This is no different for students with autism and autism like presentations, mental health or behavioral challenges, and developmental disabilities. We, as a society, must do a better job of preparing the most vulnerable graduates for interdependence and success in adulthood, and a better job of connecting them quickly with adult services that were designed for their long-term benefit. Furthermore, achieving this vision provides an advantage to both our kids and our communities at large; the longterm well-being of our most vulnerable students is synonymous with the long-term well-being of our nation.

At Ability Beyond, we believe that change is possible through Common Core standards that align with and support effective transition.

\section{Acknowledgments}

Special gratitude to members of the Connecticut Transition Task Force for their hard work on the Common Core Standards and accompanying goal bank on which our model for a seamless transition was based. The statements made herein are those of the authors and are not meant to represent opinions or policies of the Task Force or the State of Connecticut Department of Education. 


\section{Conflict of interest}

None to declare.

\section{References}

Assistance to States for the Education of Children with Disabilities and Preschool Grants for Children with Disabilities, 71 Fed. Reg. 156 (August 14, 2006) 34 C.F.R. pts 300 \& 301.

Common Core State Standards Initiative. (2015a). Closing the expectations gap 2013 Annual Report on the Alignment of State K-12 Policies and Practice with the Demands of College and Careers. Retrieved from http://www.corestandards.org/ standards-in-your-state/)

Common Core State Standards Initiative. (2015b). What parents should know. Retrieved from http://www.corestandards. org/what-parents-should-know/

Common Core State Standards Initiative. (2015c). Standards in your state. Retrieved December 15, 2015 from http://www. corestandards.org/standards-in-your-state

Connecticut State Department of Education. (2015). Common Core State Standards. Retrieved November 10, 2015 from http://www.sde.ct.gov/sde/cwp/view.asp?a=2618\&Q=320954

Connecticut Transition Task Force. (2013). Connecticut CORE Transition Skills. Retrieved from http://www.cttech.org/sss/ documents/CT\%20CORE\%20Transition\%20Skills\%20May\% 202013\%20Final2.pdf

CSDE. (2004). Topic brief: "Writing transition goals and objectives." Retrieved from http://www.sde.ct.gov/sde/lib/ sde/PDF/DEPS/Special/Transition_GO.pdfhttp://www.sde.ct. gov/sde/lib/sde/PDF/DEPS/Special/Transition_GO.pdf

Francis, G. L., Gross, J. M., Turnbull, A. P., \& Turnbull, R. (2014). Understanding barriers to competitive employment: A family perspective. Inclusion, 2(1), 37-53.

IDEA. (2004). Individuals with Disabilities Education Improvement Act, Amendments of 2004, Pub. L. No. 108-446, U.S.C. $20, \S 1400$ et seq.

Kunc, N. (1992). The Need to Belong: Rediscovering Maslow's Hierarchy of Needs.Originally published in: Villa, R., Thousand, J., Stainback, W. \& Stainback, S. Restructuring for Caring \& Effective Education. Baltimore: Paul Brookes.
Layard, R., Clark, A. E., Cornaglia, F., Powdthavee, N., \& Vernoit, J. (2014). What predicts a successful life? A life-course model of well-being. The Economic Journal, 124(580), F720-F738.

Lindsay, S., McDougall, C., Menna-Dack, D., Sanford, R., \& Adams, T. (2014). An ecological approach to understanding barriers to employment for youth with disabilities compared to their typically developing peers: Views of youth, employers, and job counselors. Disability \& Rehabilitation, 37(8), 701-711.

Novak, J. (2015). Raising expectations for US youth with disabilities: Federal disability policy advances integrated employment. CEPS Journal: Center for Educational Policy Studies Journal, 5(1), 91.

Pearpoint, J., O’Brien, J., \& Forest, M. (1993). PATH: Planning Alternative Tomorrows with Hope. Toronto: Inclusion Press.

Riesen, T., Schultz, J., Morgan, R., \& Kupferman, S. (2014) School-to-work barriers as identified by special educators, vocational rehabilitation counselors, and community rehabilitation professionals. Journal of Rehabilitation, 80(1), 33.

Ruble, L. A., \& Dalrymple, N. J. (1996). An alternative view of outcome in autism. Focus on Autism and Other Developmental Disabilities, 11(1), 3-14.

Smull, M. W., Sanderson, H., Sweeney, C., Skelhorn, L., George, A., \& Bourne, M. (2005). Essential lifestyle planning for everyone. Annapolis, MD: Learning Community-Essential Lifestyle Planning.

Stewart, C. J., Kum, H. C., Barth, R. P., \& Duncan, D. F. (2014). Former foster youth: Employment outcomes up to age 30. Children and Youth Services Review, 36, 220-229.

Theoharis, G., \& Causton, J. (2014). Leading inclusive reform for students with disabilities: A school-and systemwide approach. Theory Into Practice, 53(2), 82-97.

Wehman, P. H., Schall, C. M., McDonough, J., Kregel, J., Brooke, V., Molinelli, A., Thiss, W. et al. (2014). Competitive employment for youth with autism spectrum disorders: Early results from a randomized clinical trial. Journal of Autism And Developmental Disorders, 44(3), 487-500.

Yoshikawa, H., Aber, J. L., \& Beardslee, W. R. (2012). The effects of poverty on the mental, emotional, and behavioral health of children and youth: Implications for prevention. American Psychologist, 67(4), 272. 